\title{
A Comparative Interaction between Copper Ions with Alzheimer's $\beta$ Amyloid Peptide and Human Serum Albumin
}

\author{
G. Rezaei Behbehani, ${ }^{1}$ L. Barzegar, ${ }^{2}$ M. Mohebbian, ${ }^{1}$ and A. A. Saboury ${ }^{3}$ \\ ${ }^{1}$ Chemistry Department, Imam Khomeini International University, Qazvin 34149-16818, Iran \\ ${ }^{2}$ Chemistry Department, Faculty of Science, Islamic Azad University, Takestan Branch, Takestan 34819-49479, Iran \\ ${ }^{3}$ Institute of Biochemistry and Biophysics, University of Tehran, Tehran 14174, Iran
}

Correspondence should be addressed to G. Rezaei Behbehani, grb402003@yahoo.com

Received 2 April 2012; Accepted 15 May 2012

Academic Editor: Govindasamy Mugesh

Copyright @ 2012 G. Rezaei Behbehani et al. This is an open access article distributed under the Creative Commons Attribution License, which permits unrestricted use, distribution, and reproduction in any medium, provided the original work is properly cited.

The interaction of $\mathrm{Cu}^{2+}$ with the first 16 residues of the Alzheimer's amyliod $\beta$ peptide, $A \beta(1-16)$, and human serum albumin (HSA) were studied in vitro by isothermal titration calorimetry at $\mathrm{pH} 7.2$ and $310 \mathrm{~K}$ in aqueous solution. The solvation parameters recovered from the extended solvation model indicate that HSA is involved in the transport of copper ion. Complexes between $A \beta(1-16)$ and copper ions have been proposed to be an aberrant interaction in the development of Alzheimer's disease, where $\mathrm{Cu}^{2+}$ is involved in $A \beta(1-16)$ aggregation. The indexes of stability indicate that $\mathrm{HSA}$ removed $\mathrm{Cu}^{2+}$ from $A \beta(1-16)$ rapidly, decreased $\mathrm{Cu}$-induced aggregation of $A \beta(1-16)$, and reduced the toxicity of $A \beta(1-16)+\mathrm{Cu}^{2+}$ significantly.

\section{Introduction}

One of the hallmarks of Alzheimer's disease is the accumulation of amyloid plaques between nerve cells (neurons) in the brain. Beta amyloid is a protein fragment snipped from an amyloid precursor protein (APP). In a healthy brain, these protein fragments are broken down and eliminated. In Alzheimer's disease, the fragments accumulate to form hard, insoluble plaques. Alzheimer's disease and heart disease were made worse by excess copper and iron. Researchers are still trying to fully understand how its plaques and tangles lead to memory loss and other symptoms and how to reverse those changes to prevent or stop the disease. However, there are treatments available today that can help patients manage the symptoms of Alzheimer's disease and delay its progression. Acetylcholine helps pass messages between certain brain cells involved in memory. In Alzheimer's disease, these brain cells start to die and the amount of acetylcholine is reduced. Cholinesterase inhibitors reduce the breakdown of acetylcholine and increase its levels in the brain. This reduces some of the symptoms of Alzheimer's disease. HSA carries metal ions, including physiological $\mathrm{Ca}^{2+}, \mathrm{Zn}^{2+}, \mathrm{Co}^{2+}$, and $\mathrm{Cu}^{2+}$, as well as toxic $\mathrm{Cd}^{2+}$ and $\mathrm{Ni}^{2+}[1-5]$.
Although the etiology of cognitive impairment in Alzheimer's disease (AD) is not fully understood, it has been reported that acetylcholine-producing neurons degenerate in the brains of patients with Alzheimer's disease. The degree of this cholinergic loss has been correlated with degree of cognitive impairment and density of amyloid plaque.

Galantamine, a tertiary alkaloid, is a competitive and reversible inhibitor of acetylcholinesterase. It is possible to postulate galantamine's action therapeutic effect by enhancing cholinergic function. This is accomplished by increasing the concentration of acetylcholine through reversible inhibition of its hydrolysis by cholinesterase. If this mechanism is correct, galantamine's effect may lessen as the disease process advances and fewer cholinergic neurons remain functionally intact. In humans, $\mathrm{Cu}^{2+}$ is necessary for the development of connective tissue, nerve coverings, and bone. $\mathrm{Cu}^{2+}$ also participates in both $\mathrm{Fe}$ and energy metabolism. $\mathrm{Cu}^{2+}$ acts as a reductant in the enzymes, superoxide dismutase, cytochrome oxidase, lysyl oxidase, dopamine hydroxylase, and several other oxidases that reduce molecular oxygen. $\mathrm{Cu}^{2+}$ deficiency in humans is rare, but when it occurs it leads to normocytic, hypochromic anemia, leucopenia and neuropenia, and inclusive osteoporosis in children. Excessive dietary $\mathrm{Zn}^{2+}$ 
can cause $\mathrm{Cu}^{2+}$ deficiency. Chronic $\mathrm{Cu}^{2+}$ toxicity is rare in humans, and mostly associated with liver damage. Curcumin has been implicated in resolving and preventing Alzheimer's disease-associated plaques or deposits both in vivo and vitro. Epidemiological data suggest that the consumption of curcumin is linked to a lower incidence of Alzheimer's disease. However, the solubility of curcumin in aqueous solutions is exceedingly low, which limits its systemic absorption and therapeutic potential. A new method is proposed to treat or prevent amyloid plaque formation associated with Alzheimer's disease by injection of highly concentrated blood serum-solubilized curcumin [2, 6-10]. The objective of this study was to assess the conformational changes of HSA and $A \beta(1-16)$ due to their $A \beta(1-16)$ binding to $\mathrm{Cu}^{2+}$ ion.

\section{Materials and Method}

Human serum albumin (HSA; MW $=66411 \mathrm{gr} / \mathrm{mol}$ ) and tris salt are obtained from Sigma Chemical Co. The isothermal titration microcalorimetric experiments were performed with the four-channel commercial microcalorimetric system. Copper solution $(4 \mathrm{mM})$ was injected by use of a Hamilton syringe into the calorimetric titration vessel, which contained $1.8 \mathrm{~mL}$ HSA $(27.43 \mu \mathrm{M})$. Injection of copper solution into the perfusion vessel was repeated 28 times, with $10 \mu \mathrm{L}$ per injection. The calorimetric signal was measured by a digital voltmeter that was part of a computerized recording system. The heat of each injection was calculated by the "Thermometric Digitam 3" software program. The heat of dilution of the copper solution was measured as described above except HSA was excluded. The heats of HSA $+\mathrm{Cu}^{2+}$ interactions have been calculated in $\mathrm{kJmol}^{-1}$ and shown graphically in Figure 1.

Isothermal titration calorimetry (ITC) measurements were made on a VP-ITC ultrasensitive microcalorimeter (MicroCal, Northampton, MA) for $A \beta(1-16)+\mathrm{Cu}^{2+}$ interaction. The procedure was carried out as follows.

$\mathrm{Cu}^{2+}$ solution $(0.7 \mathrm{mM})$ and $A \beta(1-16)(75 \mu \mathrm{M})$ solution were prepared in HEPES buffer $(20 \mathrm{mM}, 150 \mathrm{mM} \mathrm{NaCl}$, pH 7.2 , at $310 \mathrm{~K})$. During the titration, $8 \mu \mathrm{L}$ of the $\mathrm{Cu}^{2+}$ solution was injected with $5 \mathrm{~min}$ intervals into the calorimetric titration vessel, which contained $1.46 \mathrm{~mL} A \beta(1-16)$. The cell was stirred at $307 \mathrm{rpm}$. The titration was conducted at $310 \mathrm{~K}$. The peptide concentrations were estimated by the BCA assay (Pierce Biotechnology). Injection of $\mathrm{Cu}^{2+}$ solution into the vessel was repeated 30 times, with $8 \mu \mathrm{L}$ per injection. The calorimetric signal was measured by a digital voltmeter that was part of a computerized recording system. The heat of each injection was calculated by the "Thermometric Digitam 3" software program. The heats of dilution of the $\mathrm{Cu}^{2+}$ solution were measured as described above excluding $A \beta(1-16)$. The heats of dilution of the $\mathrm{Cu}^{2+}$ solutions were subtracted from the enthalpies of $A \beta(1-16)+$ $\mathrm{Cu}^{2+}$ interactions. The heats of dilution of $A \beta(1-16)$ are negligible. The microcalorimeter was frequently calibrated electrically during the course of the study. The heats of $A \beta(1-$ 16) $+\mathrm{Cu}^{2+}$ interactions have been calculated in $\mathrm{kJmol}^{-1}$ and shown graphically in Figure 2.

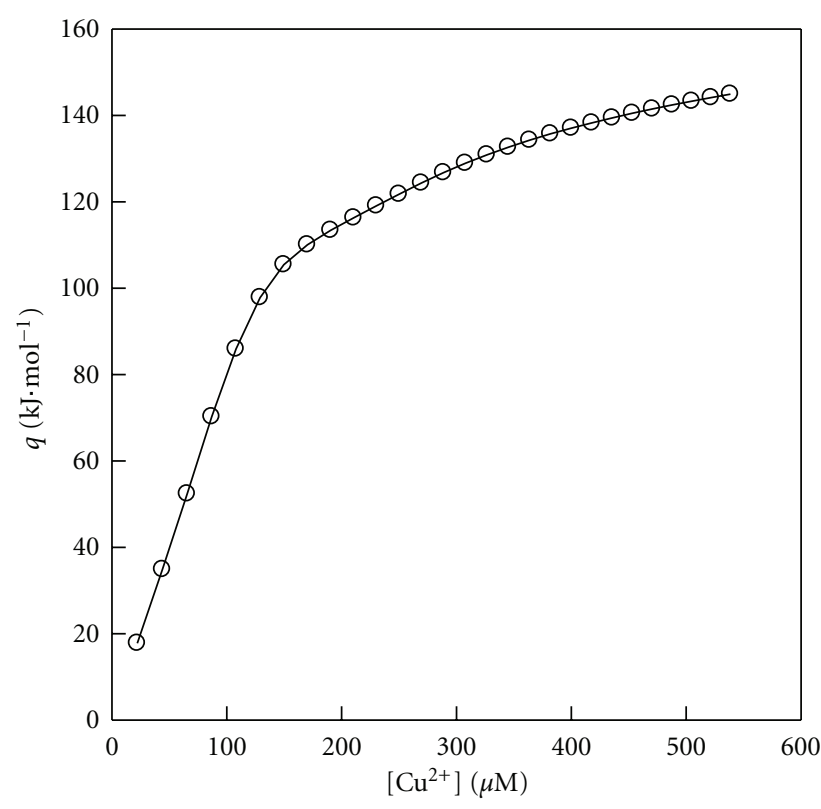

Figure 1: Comparison between the experimental heats $(\mathrm{O})$ at $310 \mathrm{~K}$, for $\mathrm{HSA}+\mathrm{Cu}^{2+}$ interactions and the calculated data (lines) via (1). $\left[\mathrm{Cu}^{2+}\right]$ values are the concentrations of $\left[\mathrm{Cu}\left(\mathrm{NO}_{3}\right)_{2}\right]$ solution in $\mu \mathrm{M}$.

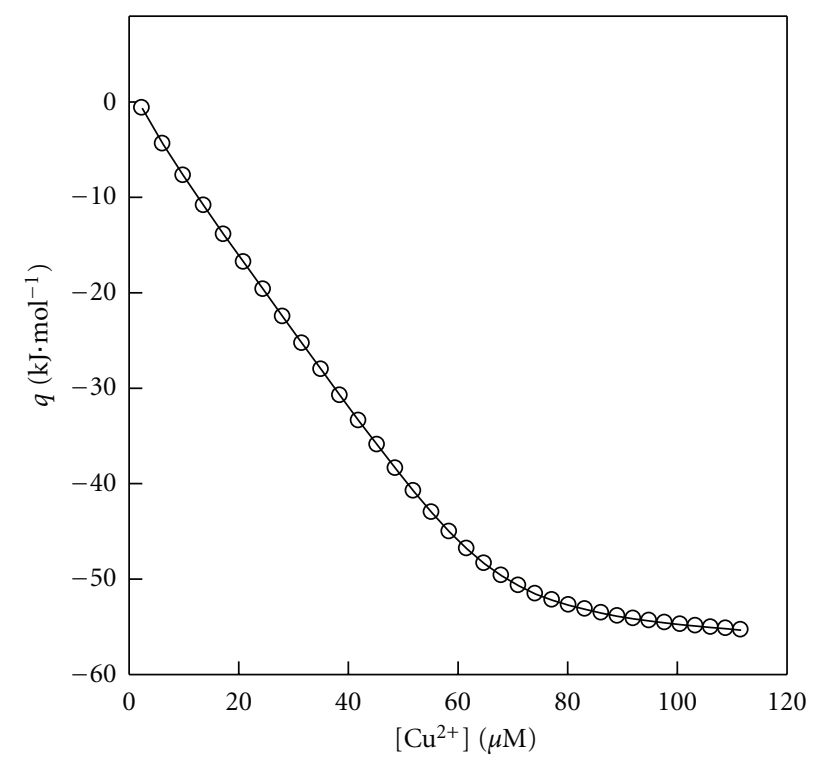

Figure 2: Comparison between the experimental heats $(\mathrm{O})$ at $310 \mathrm{~K}$, for $A \beta(1-16)+\mathrm{Cu}^{2+}$ interactions and the calculated data (lines) via (1). $\left[\mathrm{Cu}^{2+}\right]$ values are the concentrations of $\left[\mathrm{Cu}\left(\mathrm{NO}_{3}\right)_{2}\right]$ solution in $\mu \mathrm{M}$.

\section{Results and Discussion}

We have shown previously that the heats of the ligand + HSA interactions in the aqueous solvent systems, can be calculated via the following equation [10-19]:

$$
q=q_{\max } x_{B}^{\prime}-\delta_{A}^{\theta}\left(x_{A}^{\prime} L_{A}+x_{B}^{\prime} L_{B}\right)-\left(\delta_{B}^{\theta}-\delta_{A}^{\theta}\right)\left(x_{A}^{\prime} L_{A}+x_{B}^{\prime} L_{B}\right) x_{B}^{\prime},
$$


$q$ is the heats of $\mathrm{HSA}+\mathrm{Cu}^{2+}$ interactions and $q_{\max }$ represents the heat value upon saturation of all HSA or $A \beta(1-16)$. The parameters $\delta_{A}^{\theta}$ and $\delta_{B}^{\theta}$ are the indexes of the biomolecules stability in the low and high $\mathrm{Cu}^{2+}$ ion concentrations, respectively. $x_{B}^{\prime}$ can be expressed as follows:

$$
x_{B}^{\prime}=\frac{p x_{B}}{x_{A}+p x_{B}},
$$

$x_{B}^{\prime}$ is the fraction of the bound $\mathrm{Cu}^{2+}$ ion to the binding sites, and $x_{A}^{\prime}=1-x_{B}^{\prime}$ is the fraction of unbound $\mathrm{Cu}^{2+}$ ion. We can express $x_{B}$ fractions, as the total $\mathrm{Cu}^{2+}$ concentrations divided by the maximum concentration of the $\mathrm{Cu}^{2+}$ upon saturation of all HSA as follows:

$$
x_{B}=\frac{\left[\mathrm{Cu}^{2+}\right]}{\left[\mathrm{Cu}^{2+}\right]_{\max }}, \quad x_{A}=1-x_{B},
$$

$\left[\mathrm{Cu}^{2+}\right]$ is the concentration of $\mathrm{Cu}^{2+}$ ions and $\left[\mathrm{Cu}^{2+}\right]_{\max }$ is the maximum concentration of the $\mathrm{Cu}^{2+}$ ions upon saturation of all HSA. $p>1$ or $p<1$ indicates positive or negative cooperativity of a macromolecule for binding with a ligand, respectively; $p=1$ indicates that the binding is noncooperative. $L_{A}$ and $L_{B}$ are the relative contributions of unbound and bound metal ions in the heats of dilution in the absence of HSA and can be calculated from the heats of dilution of $\mathrm{Cu}^{2+}$ ions in buffer, $q_{\text {dilut }}$, as follows:

$$
L_{A}=q_{\text {dilut }}+x_{B}\left(\frac{\partial q_{\text {dilut }}}{\partial x_{B}}\right), \quad L_{B}=q_{\text {dilut }}+x_{A}\left(\frac{\partial q_{\text {dilut }}}{\partial x_{B}}\right) .
$$

The heats of HSA $+\mathrm{Cu}^{2+}$ and $A \beta(1-16)+\mathrm{Cu}^{2+}$ interactions, $q$, were fitted to ( 1 ) across the entire $\mathrm{Cu}^{2+}$ composition. In the fitting procedure, the adjustable parameter $(p)$ was changed until the best agreement between the experimental and calculated data was approached (Figures 1 and 2). The binding parameters for these interactions recovered from (1) were listed in Tables 1 and 2. The agreement between the calculated and experimental results (Figure 2) is striking, and gives considerable support to the use of $(1) . \delta_{A}^{\theta}$ and $\delta_{B}^{\theta}$ values for $\mathrm{HSA}+\mathrm{Cu}^{2+}$ interactions are positive, indicating that in the low and high concentrations of the $\mathrm{Cu}^{2+}$ ions, the HSA structure is stabilized. $p=1$ indicates that the bindingis non-cooperative. The $\delta_{A}^{\theta}$ and $\delta_{B}^{\theta}$ values for $A \beta(1-16)+$ $\mathrm{Cu}^{2+}$ interactions are negative (unstable $A \beta(1-16)+\mathrm{Cu}^{2+}$ complex), showing that the trace amounts of copper ion can induce beta-amyloid accumulation and can significantly retard the ability to learn a difficult trace conditioning task. $\mathrm{HSA}+\mathrm{Cu}^{2+}$ complex is more stable than $A \beta(1-16)+\mathrm{Cu}^{2+}$ complex, resulting in copper transfer from $A \beta(1-16)$ to human serum albumin, inhibits aggregation, and reduces $A \beta(1-16)$ toxicity. The negative $\delta_{A}^{\theta}$ and $\delta_{B}^{\theta}$ values indicate that $A \beta(1-16)+\mathrm{Cu}^{2+}$ complex is unstable, causing aggregation of $A \beta(1-16)$ peptides, which have an influence on their fibrillization. The large and positive $\delta_{A}^{\theta}$ and $\delta_{B}^{\theta}$ values show that stable $\mathrm{HSA}+\mathrm{Cu}^{2+}$ complex causes a strong tendency for transferring $\mathrm{Cu}^{2+}$ ions from $A \beta(1-16)$ to HSA and decreasing the risk of Alzheimer's disease. These interpretations show
Table 1: Binding parameters for $\mathrm{HSA}+\mathrm{Cu}^{2+}$ interaction. Positive and large $\delta_{A}^{\theta}$ and $\delta_{B}^{\theta}$ values indicate that $\mathrm{Cu}^{2+}$ could affect the structure of HSA strongly and stabilize the HSA structure significantly.

\begin{tabular}{lc}
\hline Parameters & $T=310 \mathrm{~K}$ \\
\hline$p$ & $1 \pm 0.01$ \\
$\delta_{A}^{\theta}$ & $59.06 \pm 0.18$ \\
$\delta_{B}^{\theta}$ & $58.34 \pm 0.19$ \\
\hline
\end{tabular}

TABLE 2: Binding parameters for $\mathrm{A} \beta(1-16)+\mathrm{Cu}^{2+}$ interaction. Negative $\delta_{A}^{\theta}$ and $\delta_{B}^{\theta}$ values indicate that $\mathrm{Cu}^{2+}$ could affect the structure of $\mathrm{A} \beta(1-16)$ and destabilize the $\mathrm{A} \beta(1-16)$ structure significantly. Unstable $\mathrm{A} \beta(1-16)+\mathrm{Cu}^{2+}$ complex causes the aggregation of $\mathrm{A} \beta(1-$ 16) in the brain.

\begin{tabular}{lc}
\hline Parameters & $T=310 \mathrm{~K}$ \\
\hline$p$ & $1 \pm 0.01$ \\
$\delta_{A}^{\theta}$ & $-0.17 \pm 0.05$ \\
$\delta_{B}^{\theta}$ & $-29.97 \pm 0.23$ \\
\hline
\end{tabular}

that copper transfer from $A \beta(1-16)+\mathrm{Cu}^{2+}$ to human serum albumin inhibits aggregation and reduces $A \beta(1-16)$ toxicity. Stability indexes indicate that HSA has much higher affinity for $\mathrm{Cu}^{2+}$ ions. Thereby, it is possible to propose that HSA is a good competitive reactant for removing $\mathrm{Cu}^{2+}$ ions from $A \beta(1-16)$. Copper ions in solution interact strongly with human serum albumin as evidenced by large and positive $\delta_{A}^{\theta}$ and $\delta_{B}^{\theta}$ values and stabilized the HSA structure significantly. A new method is proposed to prevent amyloid plaque formation associated with Alzheimer's disease by injection of blood serum albumin in order to keep stable $\mathrm{HSA}+\mathrm{Cu}^{2+}$ complex dominant against unstable $A \beta(1-16)+\mathrm{Cu}^{2+}$ ones. Our results have shown that HSA preferentially binds to toxic $A \beta(1-16)$ inhibiting their growth into larger $A \beta(1-16)$ assemblies.

Hopefully this suggestion proves successful, a human application would be of novel benefit for either preventing Alzheimer's disease plaque formation or possibly reverse existing plaques.

We hypothesized that $A \beta(1-16)$ aggregation induced by copper (evidenced by negative value of $\delta_{B}^{\theta}$ ) plays a key role in the neuropathology of Alzheimer's disease. The above interpretations are in agreement with our results. The association binding constants for copper with $\mathrm{A} \beta$ is much larger, while this affinity is comparatively lower for HSA. $A \beta(1-16)$ structure is destabilized greatly as a result of binding to $\mathrm{Cu}^{2+}$ ions as evidenced by -29.967 value of $\delta_{B}^{\theta}$.

\section{Conclusion}

The large and positive $\delta_{A}^{\theta}$ and $\delta_{B}^{\theta}$ values indicate that $\mathrm{Cu}^{2+}$ stabilizes the HSA structure significantly. The negative $\delta_{A}^{\theta}$ and $\delta_{B}^{\theta}$ values indicate that complexes between $A \beta(1-16)$ and copper ions have been proposed to be an aberrant interaction implicated in the development of Alzheimer's disease, where $\mathrm{Cu}^{2+}$ is involved in $A \beta(1-16)$ aggregation. The precious 
approach is that it is possible to predict a roughly treatment using the extended solvation model in vitro.

\section{Acknowledgment}

The financial support of Imam Khomeini International University and University of Tehran is gratefully acknowledged.

\section{References}

[1] H. Watanabe, U. Kragh-Hansen, S. Tanase et al., "Conformational stability and warfarin-binding properties of human serum albumin studied by recombinant mutants," Biochemical Journal, vol. 357, no. 1, pp. 269-274, 2001.

[2] T. Peters, "Serum albumin," Advances in Protein Chemistry, vol. 37, pp. 161-245, 1985.

[3] F. Kratz, "Albumin as a drug carrier: design of prodrugs, drug conjugates and nanoparticles," Journal of Controlled Release, vol. 132, no. 3, pp. 171-183, 2008.

[4] G. R. Behbehani, A. Divsalar, A. A. Saboury, and M. J. Bagheri, "A thermodynamic study on the binding of human serum albumin with new synthesized anti cancer Pd (II) complex," Journal of Solution Chemistry, vol. 37, no. 12, pp. 1785-1794, 2008.

[5] D. C. Carter and J. X. Ho, "Structure of serum albumin," Advances in Protein Chemistry, vol. 45, pp. 153-203, 1994.

[6] X. M. He and D. C. Carter, "The conformation of serum albumin in solution: a combined phosphorescence depolarizationhydrodynamic modeling study," Nature, vol. 358, no. 6383, pp. 209-215, 1992.

[7] J. N. Zvimba and G. E. Jackson, "Thermodynamic and spectroscopic study of the interaction of $\mathrm{Cu}(\mathrm{II}), \mathrm{Ni}(\mathrm{II}), \mathrm{Zn}(\mathrm{II})$ and $\mathrm{Ca}(\mathrm{II})$ ions with 2-amino-N-(2-oxo-2-(2-(pyridin-2-yl)ethyl amino)ethyl)acetamide, a pseudo-mimic of human serum albumin," Polyhedron, vol. 26, no. 12, pp. 2395-2404, 2007.

[8] C. G. Fraga, "Relevance, essentiality and toxicity of trace elements in human health," Molecular Aspects of Medicine, vol. 26, no. 4-5, pp. 235-244, 2005.

[9] G. R. Behbehani and M. Mirzaie, "A high performance method for thermodynamic study on the binding of copper ion and glycine with Alzheimer's amyloid $\beta$ peptide," Journal of Thermal Analysis and Calorimetry, vol. 96, no. 2, pp. 631-635, 2009.

[10] G. R. Behbehani, A. Divsalar, A. A. Saboury, F. Faridbod, and M. R. Ganjali, "A high performance method for thermodynamic study on the binding of human serum albumin with erbium chloride," Journal of Thermal Analysis and Calorimetry, vol. 96, no. 2, pp. 663-668, 2009.

[11] G. R. Behbehani, A. A. Saboury, A. F. Baghery, and A. Abedini, "Application of an extended solvation theory to study on the binding of magnesium ion with myelin basic protein," Journal of Thermal Analysis and Calorimetry, vol. 93, no. 2, pp. 479483, 2008.

[12] G. R. Behbehani, A. Divsalar, A. A. Saboury, and A. Hekmat, "A thermodynamic study on the binding of PEG-stearic acid copolymer with lysozyme," Journal of Solution Chemistry, vol. 38, no. 2, pp. 219-229, 2009.

[13] G. R. Behbehani, A. A. Saboury, and A. F. Baghery, "A thermodynamic study on the binding of calcium Ion with myelin basic protein," Journal of Solution Chemistry, vol. 36, no. 10, pp. 1311-1320, 2007.

[14] G. R. Behbehani, A. A. Saboury, and E. Taleshi, "A comparative study of the direct calorimetric determination of the denaturation enthalpy for lysozyme in sodium dodecyl sulfate and dodecyltrimethylammonium bromide solutions," Journal of Solution Chemistry, vol. 37, no. 5, pp. 619-629, 2008.

[15] G. R. Behbehani and A. A. Saboury, "A new method for thermo- dynamic study on the binding of magnesium with human growth hormone," Journal of Thermal Analysis and Calorimetry, vol. 89, pp. 852-861, 2007.

[16] G. R. Behbehani, A. A. Saboury, and E. Taleshi, "Determination of partial unfolding enthalpy for lysozyme upon interaction with dodecyltrimethylammonium bromide using an extended solvation model," Journal of Molecular Recognition, vol. 21, no. 2, pp. 132-135, 2008.

[17] G. R. Behbehani, A. A. Saboury, and E. Taleshi, "A direct calorimetric determination of denaturation enthalpy for lysozyme in sodium dodecyl sulfate," Colloids and Surfaces B, vol. 61, no. 2, pp. 224-228, 2008.

[18] G. R. Behbehani, A. A. Saboury, E. Poorakbar, and L. Barzegar, "Application of the extended solvation model for thermodynamic study of copper ion binding to Jack bean urease," Journal of Thermal Analysis and Calorimetry, vol. 102, no. 3, pp. 1141-1146, 2010.

[19] B. G. Rezaei, "A novel method for thermodynamic study on binding of copper ion with Alzheimer's amyliod $\beta$ peptide," Chinese Science Bulletin, vol. 54, no. 6, pp. 1037-1042, 2009. 


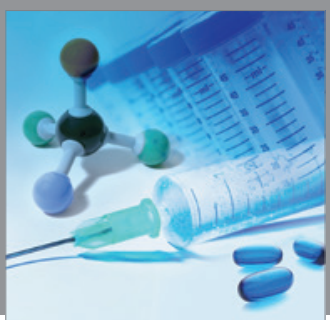

International Journal of

Medicinal Chemistry

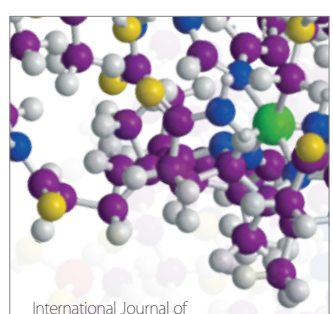

Carbohydrate Chemistry

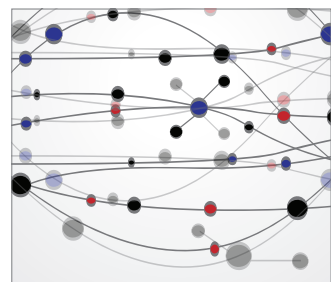

The Scientific World Journal
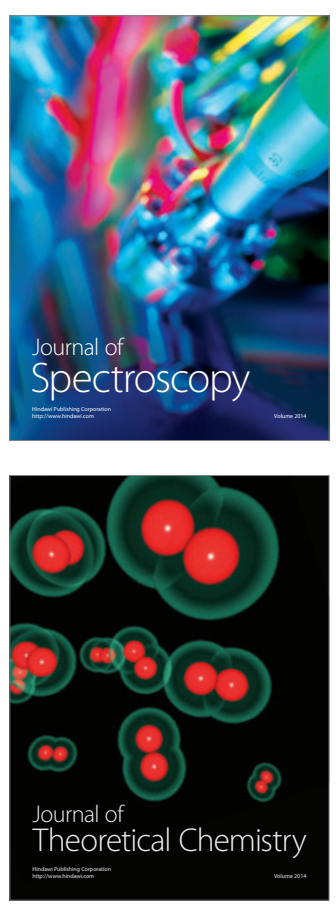
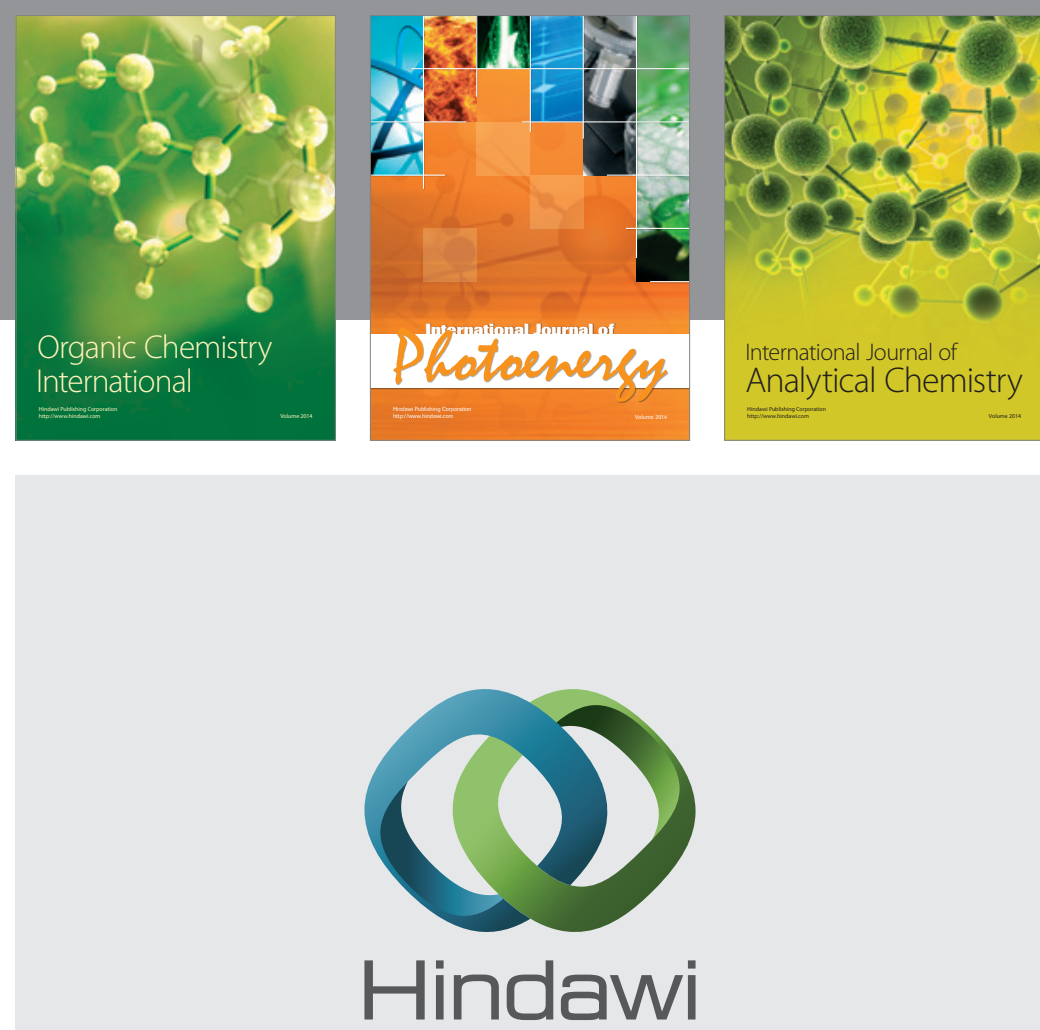

Submit your manuscripts at

http://www.hindawi.com
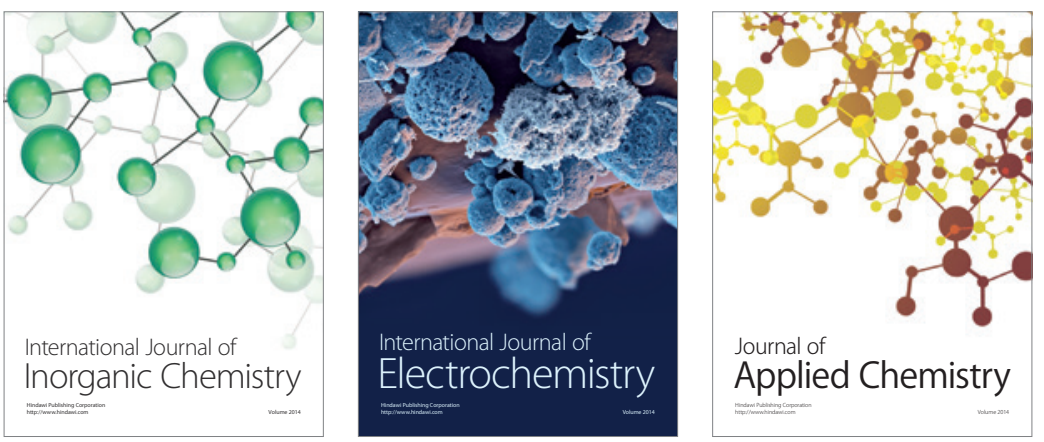

Journal of

Applied Chemistry
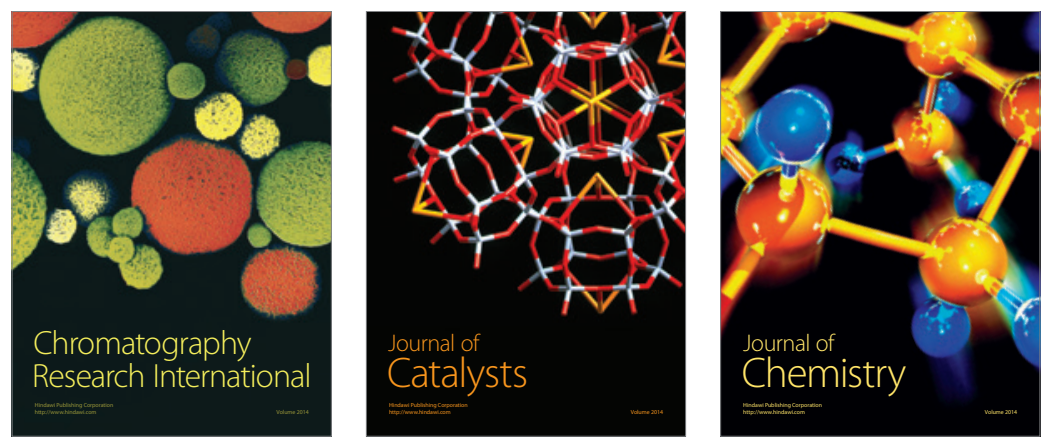
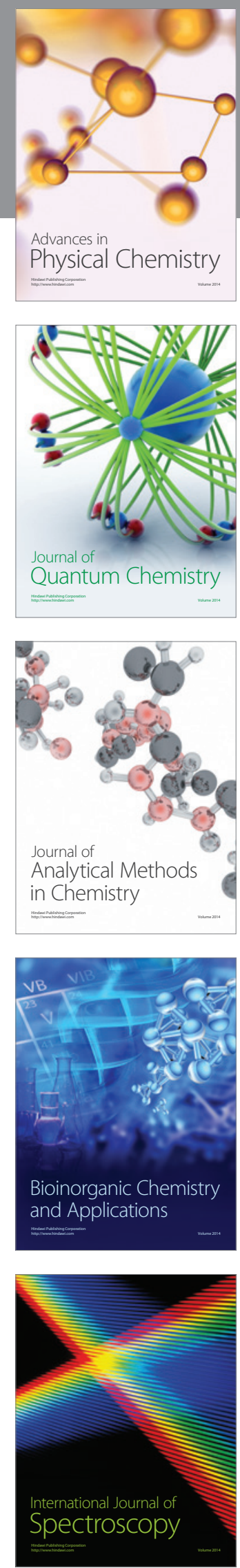